\title{
PENGARUH MODEL PROBING PROMTING BERBASIS KEARIFAN LOKAL TERHADAP SIKAP CINTA LINGKUNGAN PESERTA DIDIK KELAS IV
}

\author{
Alfia Ratnawati ${ }^{1}$, Yusuf ${ }^{2}$, Ema Butsi Prihastari ${ }^{3}$ \\ Jurusan Ilmu Pendidikan, PGSD, Universitas Slamet Riyadi \\ Email: alfiaratnawati@gmail.com
}

\begin{abstract}
Abstrak
The purpose of this research was to study the attitude of environmental love of students in grade IV of SD Negeri Kauman No.27 Surakarta with an influence probing promting model based on local wisdom in the discussion of shapes in the Academic Year 2018/2019. This research was quantitative research with the design of One Group Pretest-Posttest Design. The population of all grade IV students of Kauman State No.27 Surakarta in Academic Year 2018/2019 gathered 32 students with saturated sampling techniques. Data collection techniques were in this study through questionnaires, observation, interviews, and documentation. The data analysis technique used paired sample t-test. Based on the results of data analysis, the value of accounting is 3,869. While tcount is compared with t table with $d . b=(N-1)=(32-1)$ at a significance level of $5 \%=2,040$ or obtained tcount $(3,869)>$ ttable $(2,041)$. So, it can be announced that "Probing Promting Models Based on Local Wisdom Towards Environmental Attitudes of Class IV Students in Shapes Discussion.
\end{abstract}

Keywords: probing promting model, local wisdom, environmental attitudes

\begin{abstract}
Abstrak
Tujuan penelitian ini untuk mengetahui sikap cinta lingkungan peserta didik kelas IV SD Negeri Kauman No.27 Surakarta melalui model probing promting berbasis kearifan lokal dalam pembahasan bangun datar Tahun Pelajaran 2018/2019. Jenis penelitian yang digunakan adalah penelitian kuantitatif dengan desain One Group Pretest -Posttest Design. Populasinya seluruh peserta didik kelas IVSD Negeri Kauman No.27 Surakarta Tahun Pelajaran 2018/2019 yang berjumlah 32 peserta didik dengan teknik sampling jenuh. Teknik pengumpulan data pada penelitian ini melalui angket, observasi, wawancara, dan dokumentasi. Teknik analisis data menggunakan uji paired sample t-test. Berdasarkan hasil analisis data diperoleh hasil nilai $t_{\text {hitung }}$ sebesar 3,869. Sedangkan $t_{\text {hitung }}$ dibandingkan dengan $t_{\text {tabel }}$ dengan d.b $=(\mathrm{N}-1)=(32-1)$ pada taraf signifikansi $5 \%=2,040$ atau diperoleh $t_{\text {hitung }}(3,869)>t_{\text {tabel }}(2,041)$. Jadi, dapat dinyatakan bahwa "Ada Pengaruh Model Probing Promting Berbasis Kearifan Lokal Terhadap Sikap Cinta Lingkungan Peserta Didik Kelas IV dalam Pembahasan Bangun Datar.
\end{abstract}

Kata Kunci: model probing promting, kearifan lokal, sikap cinta lingkungan. 


\section{PENDAHULUAN}

Pendidikan Nasional

berdasarkan Pancasila dan UndangUndang dasarNegara Republik Indonesia berfungsi untuk mengembangkan kemampuan dan membentuk watak serta peradaban bangsa yang bermartabat dalam rangka mencerdaskan kehidupan bangsa. Untuk itu Pendidikan Nasional bertujuan untuk mengembangkan potensi peserta didik agar menjadi manusia yang beriman dan bertaqwa kepada Tuhan Yang Maha Esa, berakhlak mulia, sehat, berilmu, cakap, kreatif, mandiri, dan menjadi warga Negara yang demokratis serta bertanggung jawab. Menurut (UU No.20 tahun 2003) tentang sistem pendidikan nasional.

Pendidikan di sekolah merupakan suatu proses yang melibatkan guru dan peserta didik. Proses pembelajaran kurikulum 2013 peserta didik dituntut untuk lebih aktif, namun pada kenyataannya peserta didik masih pasif saat pembelajaran berlangsung. Proses pembelajaran juga merupakan sesuatu yang rumit karena guru tidak hanya mentransfer informasi dan ilmu pengetahuan, akan tetapi guruharus melibatkan peserta didik untuk melakukan berbagai tindakan dan juga praktek. Hal tersebut bertujuan agar peserta didik mampu memahami materi dengan baik, sehingga dapat menciptakan pembelajaran yang berkualitas.Penerapan Model pembelajaran yang sesuai dengan karakter peserta didik dapat memudahkan peserta didik memahami materi yang disampaikan, sehingga tujuan pembelajaran dapat tercapai. Salah satu model pembelajaran tertentu akan mempengaruhi hasil belajar serta sikap peserta didik sesuai dengan tujuan yang ingin dicapai

Pendidikan kearifan lokal mengangkat berbagai pengetahuan kebudayaan setempat yang bertujuan untuk memupuk kembali budi pekerti luhur, cinta lingkungan dan bangga terhadap sesuatu yang dimiliki negara Indonesia, mengembalikan karakter bangsa yang cinta lingkungan dan berbudaya, karena sejatinya pendidikan dan kebudayaan itu tidak terpisahkan. 
Model pembelajaran dapat juga mengajarkan siswa akan membangkitkan keinginan, minat, pentingya Guru membutuhkan motivasi dan rangsangan kegiatan pendekatan, strategi, dan model belajar, bahkan membawa pengaruhpengaruh psikologis terhadap peserta didik. Selain itu, model pembelajaran membantu peserta didik meningkatkan sikap cinta lingkungan yaitu kesadaran akan pentingnya menjaga lingkungan.

Berdasarkan hasil observasi yang dilakukan di SD Negeri Kauman No.27 Surakarta Tahun Pelajaran 2018/2019, didapatkan hasil bahwa masih rendah, masih banyak anakanak yang terbiasa membuang sampah di sembarang tempat seperti membuang sampah di laci meja ketika di dalam kelas bahkan ada juga yang menbuang sampah pada pot bunga serta tidak hemat energi pada saat siswa sedang mencuci tangan banyak siswa yang tidak menutup kembali kran air, kesadaran akan pentingnya peduli lingkungan harus di tingkatkan sedini mungkin agar siswa sadar dan terbiasa akan pentingnya menjaga lingkungan sekitar.

Guru tidak hanya membimbing siswa dalam kesulitan belajar namun belajar yang tepat dalam menyampaikan pertanyaan agar siswa terlihat dalam proses berpikir menemukan jawaban sendiri dengan bimbingan guru. Salah satu model yang diperlukan pada masalah yang ditemui di lapangan yaitu model probing promting. Dimana siswa seharusnya di belajarkan melalui pemberian stimulus proses berpikir siswa.

Berdasarkan permasalahan yang dijumpai di lapangan, perlu adanya evaluasi terhadap pengajaran guru dan respon siswa.Maka perlu adanya model pembelajaran yang menarik dan dapat menumbuhkan karakter cinta lingkungan siswa. Model pembelajaran probing promting berbasis kearifan lokal, akan membantu siswa dalam meningkatkan hasil belajar sekaligus membantu dalam terwujudnya pembangunan karakter sikap cinta terhadap lingkungan.

Menurut Miftahul Huda (2013:281) pembelajaran probing promting adalah pembelajaran yang 
Jurnal Sinektik

Volume 2 Nomor 2, Edisi Desember 2019

Prodi PGSD Universitas Slamet Riyadi

ISSN 2620-6560 (print) ISSN 2620-746X (online)

menyajikan serangkaian pertanyaan

yang bersifat menuntun dan menggali

sehingga memungkinkan terjadinya

proses berpikir siswa dalam

mengaitkan pengetahuan setiap siswa

dan pengalamanya dengan

pengetahuan baru. Model ini

memiliki tahapan mulai dari

penyajian masalah, memberikan

pertanyaan menuntun kearah materi,

memberikan kesempatan berpikir

hingga memberikan pertanyaan yang

sifatnya menggali pengetahuan siswa.

Pengetahuan baru dikaitkan dengan pengalaman siswa mengenai kebudayaan lokal seperti tempat wisata disekitar lingkungan siswa tinggal atau belajar, dalam hal ini daerah Surakarta maka disajikan serangkaian pertanyaan tentang obyek wisata salah satunya Keraton Surakarta dan candi cetho di daerah Karangganyar sehingga di jadikan model probing promting berbasis kearifan lokal. Penelitian sebelumnya yang mengangkat model ini di lakukan

Berdasarkan dari uraian di atas, maka peneliti mengambil judul penelitian yaitu "Pengaruh Model Probing Promting Berbasis Kearifan lokal Terhadap Sikap Cinta Lingkungan Peserta Didik Kelas IV dalam Pembahasan Bangun Datar (Studi Eksperimen di SD Negeri Kauman No.27 Surakarta Tahun Pelajaran 2018/2019)".

\section{METODE PENELITIAN}

Penelitian ini dilaksanakan di SD Negeri Kauman No.27, Kelurahan Kedunglumbu, kecamatan Pasarkliwon, kota Surakarta. Penelitian ini dilakukan di kelas IV SD Negeri Kauman No. 27 Surakarta. Penelitian ini dilaksanakan pada semester genap Tahun Pelajaran 2018/2019 pada bulan Januari 2018 s.d. Juni 2019.

Jenis penelitian ini yaitu one group pretest-posttes design". Populasi dalam penelitian ini adalah seluruh peserta didik kelas IV SD Negeri Kauman No.27 Surakarta Tahun Pelajaran 2018/2019, dengan jumlah 32 peserta didik. Sampel dalam penelitian ini adalah seluruh peserta didik kelas IV SD Negeri Kauman No.27 Surakarta Tahun Pelajaran 2018/2019, dengan jumlah 32 peserta didik.Teknik pengumpulan data dalam penelitian ini adalah 
observasi, wawancara, angket dan dokumentasi.

Penelitian ini terdapat dua variabel yaitu variabel independen yaitu model probing promting berbasis kearifan lokal, sedangkan variabel dependennya yaitu sikap cinta lingkungan dalam pembahasan bangun datar. Uji coba dalam penelitian ini menggunakan validitas dengan rumus korelasi Product Moment dan Uji Reliabilitas dengan rumus Alpha Cronbach. Teknik analisis data penelitian ini menggunakan uji paired sample $t_{-}$ test.

\section{HASIL DAN PEMBAHASAN}

Penelitian ini merupakan jenis penelitian pre-eksperimental one group pretest-post test design dilakukan pada peserta didik kelas IV SD Negeri Kauman No.27 Surakarta Tahun Pelajaran 2018/2019. Penelitian ini mengangkat variabel bebas yaitu model probing promting dan variabel terikat sikap cinta lingkungan dalam pembahasan bangun datar. Populasi dari penelitian ini adalah peserta didik kelas IV SD
Negeri Kauman No.27 Surakarta Tahun Pelajaran 2018/2019.

\section{Deskripsi Data Sikap Cinta Lingkungan Peserta Didik dalam Pembahasan Bangun Datar. \\ Hasil data pretest peserta} didik kelas IV dengan nilai tertinggi 63-66 berjumlah 2 peserta didik, nilai terendah 42-44 berjumlah 1 peserta didik, nilai yang sering muncul 51-53 berjumlah 2 peserta didik.

2. Deskripsi Data Sikap Cinta Lingkungan Peserta Didik dalam Pembahasan Bangun Datar. Sesudah Menggunakan Model Probing Promting Berbasis Kearifan lokal.

Hasil data Posttest peserta didik kelas IV, diperoleh nilai tertinggi 67-74 berjumlah 1 peserta didik, dan nilai terendah 47-51 berjumlah 5 peserta didik, serta nilai yang sering muncul 62-66 berjumlah 9 peserta didik.

\section{Pengujian Hipotesis}

a. Uji Prasyarat Analisis

(Normalitas)

Data pretest diperoleh nilai sig (2-tailed) $0,785>0,05$ dan 
posttest $0,920>0,05$, sehingga

Ho diterima. Jadi dapat disimpulkan bahwa data pretest dan posttest berdistribusi normal.

b. Uji Paired Sample T-Test

Dari hasil analisis data dengan menggunakan uji paired sample t-test diperoleh hasil nilai $t_{\text {hitung }}$ sebesar 3,869 Sedangkan $t_{\text {hitung dibandingkan dengan }}$ $\mathrm{t}_{\text {tabel }}$ dengan d.b $=(\mathrm{N}-1)=(32-$ 1) $=31$ pada taraf signifikansi $5 \%=2.041$ sedangkan menurut nilai sig didapatkan hasil 0,000 $<0,05$. Jadi dapat disimpulkan bahwa $t_{\text {hitung }}>t_{\text {tabel }}$ atau 3,869 > 2.041yang berarti bahwa $\mathrm{Ha}$ diterima dan Ho ditolak.

Dapat disimpulkan dari perhitungan $t$-test dengan nilail $\operatorname{sig} 0,000<0,05$ dan $t_{\text {hitung }}>$ $\mathrm{t}_{\text {tabel }}$ atau $3,869>2,041$ maka hipotesis : Ada pengaruh model probing promting berbasis kearifan lokal terhadap sikap cinta lingkungan peserta didik kelas IV dalam pembahasan bangun datar di SDNegeri Kauman No.27 Surakarta Tahun Pelajaran 2018/2019.
Berdasarkan hasil uji hipotesis di atas dapat diterima dengan baik, pada taraf signifikansi 5\% bahwa "Ada Pengaruh Model Probing Promting Berbasis Kearifan Lokal Terhadap Sikap Cinta Lingkungan Peserta Didik Kelas IV dalam Pembahasan Bangun datar di SD Negeri Kauman No.27 Surakarta Tahun Pelajaran 2018/2019”.

Hasil analisis data dapat dijelaskan bahwa model probing promting berbasis kearifan lokal berpengaruh positif terhadapsikap cinta lingkungan peserta didik kelas IVdalam pembahasan bangun datar di SD Negeri Kauman No.27 Surakarta Tahun Pelajaran 2018/2019.Dapat dipaparkan bahwa dampak yang muncul dari kegiatan pembelajaran menggunakan model probing promting berbasis kearifan lokal dapat membantu peserta didik dalam pemahaman materi pelajaran matematika khususnya dalam pembahasan bangun datar, selain itu dengan model probing promting berbasis kearifan lokal ini juga dapat mengajarkan peserta didik tentang kearifan lokal yang ada dilingkungan peserta didik. Dampak yang nyata 
bagi peserta didik dengan pembelajaran menggunakan model probing promting berbasis kearifan lokal ini adalah peserta didik lebih tertarik untuk belajar matematika, yang mana matematika dianggap sebagai pelajaran yang sulit dan membosankan. Selain itu, peserta didik juga dapat mengetahui kearifan lokal yang ada disekitar lingkungannya yang berdampak pada munculnya perubahan sikap kecintaan peserta didik terhadap lingkungan dan rasa ingin tahu tentang kearifan lokal budaya yang ada disekitar mereka khususnya pada tempat wisata bangunan masjid Agung dan Keraton yang ada di Surakartaa.

Hal ini sesuai dengan teori belajar dalam Hamzah Uno (2006: 7). Teori Behavioristik merupakan teori dengan pandangan tetang belajar adalah perubahan dalam tingkah laku sebagai akibat dari interaksi antara stimulus dan respon. Atau dengan kata lain belajar adalah perubahan yang dialami siswa dalam hal kemampuannya untuk bertingkah laku dengan cara yang baru sebagai hasil interaksi antara stimulus dan respon. Mohammad Saroni (2017:4647) menjelaskan sikap adalah kemampuan dasar yang dimiliki sejak kita dilahirkan ke dunia. Setiap orang membawa sikap ini sebagai ciri khasnya sebagai mahluk hidup. Dengan sikap ini, kita dapatmenjalani kehidupan ini dengan sebaik-baiknya. Menurut Amirullah Syarbini (2014:17) cinta kebaikan (loving the good) cinta kebaikan merupakan bentuk tertinggi dari karakter. Ketika orang-orang sudah mencintai kebaikan, mereka pasti senang untuk melakukan kebaikan.

Hasil tersebut sejalan dengan penelitian Damar (2017) ini menyatakan hasil pembelajaran metematika berbasis kearifan lokal menunjukan bahwa ada peningkatan prestasi. Kemudian penelitian ini juga didukung oleh penelitian Ema Butsi Prihastari dan Ratna Widyaningrum (2018) menunjukan bahwa terdapat perbedaan yang signifikan antara sebelum dan sesudah menggunakan media MAS NOVEL berbasis kearifan lokal terhadap penanaman karakter peduli lingkungan. Sejalan dengan penelitian ini, karena ada pengaruh dari variabel bebas terhadap 
variabel terikatnya, didukung pula dengan penelitian Yora Harlistyarintica, dkk (2017) menunjukan bahwa dengan program jari kreasi sampah bocah cilik dapat menumbuhkan rasa cinta terhadap lingkungan sejak usia dini.Hal ini sejalan dengan penelitian ini karena ada pengaruh model yang digunakan terhadap sikap cinta lingkungan.

\section{SIMPULAN}

Berdasarkan hasil penelitian dan analisis data dapat disimpulkan bahwa model probing promting berpengaruh terhadap sikap cinta lingkungan peserta didik kelas IV dalam pembahasan bangun datar di SD Negeri Kauman No.27 Surakarta. Dari perhitungan uji hipotesis dengan bantuan program SPSS 16, dapat dilihat jika signifikansi (2 tailed) > 0,05 maka Ho diterima. Terlihat uji paired sample t-test diperoleh hasil nilai Hasil penelitian menunjukan mean dari nilai pretest sikap cinta lingkungan peserta didik yaitu 54,88 dan mean dari nilai posttest sikap cinta lingkungan peserta didikyaitu 58,66. Sehingga menunjukan bahwa nilai posttest lebih besar daripada nilai pretest, dengan rata-rata 3,78 . Dari perhitungan uji hipotesis dengan bantuan program SPSS 16, dapatdiketahui bahwa besar pengaruh nilai pretest dan posttest adalah 0,610 dengan nilai signifikansi 0,000 . Dengan hasil uji paired sample t-test di peroleh nilai $t_{\text {hitung }}$ sebesar 3,869. Sedangkan $t_{\text {hitung dibandingkan }}$ dengan $t_{\text {tabel }}$ dengan d. $b=(\mathrm{N}-1)=(32-$ 1) $=31$ pada taraf signifikansi $5 \%=$ 2,040 atau diperoleh $t_{\text {hitung }}=3,869>$ $t_{\text {hitung }}=2,041$ sehingga Ho ditolak dan Ha diterima. Maka hipotesis : Ada Pengaruh Model Probing Promting Berbasis Kearifan Lokal Berpengaruh Terhadap Sikap Cinta Lingkungan dalam Pembahasan Bangun Datar Peserta Didik Kelas IV Sekolah Dasar Negeri Kauman No.27 Surakarta Tahun Pelajaran 2018/2019, terbukti kebenarannya dengan taraf signifikansi $5 \%$.

Saran yang dapat diberikan dalam penelitian ini antara lain adalah sebagai berikut:

1. Untuk Peserta Didik

Peserta didik diharapkan lebih fokus saat mengikuti pembelajaran dan bertanya saat tidak memahami materi yang diajarkan oleh guru 
serta ikut andil pada saat proseb belajar ataupun pada saat berdiskusi kelompok agar dapt memahami materi yang diberikan.

2. Untuk Guru

Guru diharapkan dapat lebih kreatif dan inovatif dalam memilih model pembelajaran yang relevan dengan materi yang diajarkan, sehingga pembelajaran dapat menarik perhatian peserta didik.

3. Untuk Sekolah

Bagi sekolah, peneliti mengharapkan agar pihak sekolah mengadakan pelatihan tentang peningkatan kreatifitas dalam penggunaan model pembelajaran sehingga guru mampu dalam mengimplementasikan berbagai strategi maupun teknik pembelajaran.

4. Bagi Peneliti

Peneliti selanjutnya hendaknya megunakan model probing promting berbasis kearifan lokal untuk menumbuhkan sikap cinta lingkungan peserta didik sehingga peserta didik mendapatkan hasil yang maksimal.

\section{DAFTAR PUSTAKA}

Amirullah Syarbini. 2014. Model Pendidikan Karakter Dalam Keluarga. Jakarta : PT Gramedia.

Annas Salahudin. 2013. Pendidikan Karakter Berbasis Kearifan Lokal Di Sekolah. Yogyakarta: Pustaka Pelajar.

Arif Rahman Hikam, Nana Kariada dan Kukuh Santosa. 2013. Pengembangan Game Edukasi Visual Novel Berbasis Pembangunan Karakter Pada Materi Pelestarian Lingkungan. Journal Of Biology Education. Unnes. 2(2).148-155

Damar Januarti dan Sutoyo. 2017. Penerapan Model Probing Prompting Berbasis Kearifan Lokal Untuk Meningkatkan Prestasi Belajar Pada Materi Bilangan Desimal Dan Persen Pada Siswa Kelas IV Sekolah Dasar. Skripsi. Universitas Slamet Riyadi

Ema Butsi Prihastari dan Ratna Widyaningrum. 2015. Analisis Berpikir Kritis Siswa Kelas V Pada Materi Geometri Dengan Teknik Scaffolding. Jurnal Profesi Pendidikan.10(1). Hal.95-102

Ema Butsi Prihastari dan Ratna Widyaningrum. 2018. Implementasi Media Mas Novel Berbasis Kearifan Lokal Untuk Penanaman Karakter Peduli Lingkungan Pada Siswa SD. Seminar Nasional Pendidikan $U M S$. 
Volume 2 Nomor 2, Edisi Desember 2019

Prodi PGSD Universitas Slamet Riyadi

ISSN 2620-6560 (print) ISSN 2620-746X (online)

Hamzah Uno. 2006. Perkembangan

Peserta Didik. Yogyakarta :

Kurnia Kalam Semesta

Miftahul Huda. 2014. Model-model

Pengajaran dan Pembelajaran

(Isu-isu Metodis dan

Pragmatis).Yogyakarta:

Pustaka Pelajar.

Muhammad Saroni. 2017. Langkah

Efektif Meningkatkan Kualitas

Karakter Warga Sekolah.

Yogyakarta : Ar-Ruzz Media.

Yora Harlistyarintica, dkk. 2017. Penanaman Pendidikan Karakter Cinta Lingkungan Melalui Jari Kreasi Sampah Bocah Cilik Di Kawasan Parangtritis. Jurnal Pendidikan Anak. 6(1).20-30 
Jurnal Sinektik

Volume 2 Nomor 2, Edisi Desember 2019

Prodi PGSD Universitas Slamet Riyadi

ISSN 2620-6560 (print) ISSN 2620-746X (online) 